\title{
Comparison of glucose degradation product and receptor levels in diabetic and normal pregnancy
}

\author{
(D) Özlem Şimşek Tanin 1 , (D) Mustafa Kara² , (D) Yaprak Engin-Üstün ${ }^{3}$, (D) Ayşe Yeşim Göçmen ${ }^{4}$, (D) Ethem Serdar Yalvaç5 \\ ${ }^{1}$ Clinic of Obstetrics and Gynecology, Boğazlıyan State Hospital, Yozgat, Turkey \\ 2Department of Obstetrics and Gynecology, Kırşehir Ahi Evran University Faculty of Medicine, Kırşehir, Turkey \\ 32Department of Obstetrics and Gynecology, University of Health Sciences Turkey, Ankara Etlik Zübeyde Hanım Women's \\ Health and Research Center, Ankara, Turkey \\ 4Department of Medical Biochemistry, Yozgat Bozok University Faculty of Medicine, Yozgat, Turkey \\ 5Department of Obstetrics and Gynecology, Yozgat Bozok University Faculty of Medicine, Yozgat, Turkey
}

\section{Abstract}

Objective: The aim of this study was to assess the diagnostic values of new biochemical markers that may be an alternative to the oral glucose tolerance test (OGTT) and determine the differences in these markers among three groups of women with varying degrees of glucose homeostasis dysregulation.

Material and Methods: This was a prospective study. All women were screened with 50 gram (g) oral glucose and a $100 \mathrm{~g}$ OGTT for gestational diabetes mellitus (GDM). The patients were divided into three groups depending on the result of the tests: no evidence of glucose metabolism abnormality (controls); impaired glucose tolerance (IGT); and GDM. All three groups were evaluated for serum human advanced glycation endproducts (AGEs) concentrations, carboxymethyl lysine (CML) concentration and receptor for advanced glycation end-product concentrations (RAGE/AGER), body mass index (BMI), age, fasting glucose levels, obstetrical parameters and gestational age.

Results: The study included 180 women divided into 59 (32.8\%) GDM, 50 (27.8\%) IGT and 71 (39.4\%) controls. Age was similar among the three groups. Whereas fasting glucose levels and BMI in the three groups was significantly different, AGEs, CML, RAGE/AGER levels were found as significantly different between the groups $(\mathrm{p}<0.001)$.

Conclusion: In this study the use of AGEs, CML, and RAGE/AGER concentrations for the diagnosis and screening of gestational diabetes was investigated. It was found that advanced glycation products were significantly elevated in pregnancies with both IGT and GDM. These biochemical markers of glucose homeostasis dysregulation may have potential for GDM screening in the future. (J Turk Ger Gynecol Assoc 2021; 22: 127-31)

Keywords: Gestational diabetes mellitus, RAGE/AGER, CML, impaired glucose intolerance

Received: 04 April, 2020 Accepted: 04 June, 2020

\section{Introduction}

There is no complete consensus on the diagnosis, screening, follow-up and treatment of gestational diabetes mellitus (GDM). GDM is the leading cause of maternal and fetal morbidity and perinatal mortality; the rates of fetal loss and illness in GDM pregnancies are about four times higher compared to normal pregnancies (1). The world's most common screening test is 50 gram (g) (1-hour) glucose test and its sensitivity is between
$60 \%$ and $80 \%$. A $100 \mathrm{~g}$ oral glucose tolerance test (OGTT) is used as a diagnostic test. Impaired glucose tolerance (IGT) has been shown to be an inter-metabolic disorder, between normal glucose tolerance and diabetes (prediabetes). IGT is a major risk factor for DM and it has been shown that, within 10 years, progression to full diabetes is between $20-50 \%$ ratio (2). Regulation of blood sugar levels following a GDM diagnosis during pregnancy prevents fetal macrosomia, which is associated with shoulder dystocia, birth trauma, and increased 
rate of cesarean section. In addition, metabolic complications such as hypoglycemia, polycythemia, hypocalcemia and hyperbilirubinemia, which occur in the neonatal period, can be prevented to a not insubstantial extent and maternal and fetal morbidity and mortality can be reduced (3).

Although there is some controversy concerning the definition of GDM, there is a close relationship between GDM and perinatal morbidity and mortality. Therefore, accurate and timely diagnosis and treatment have gained importance. OGTT has been used for the diagnosis of diabetes for years. OGTT criteria are frequently updated by organizations such as the American Diabetes Association (ADA) and the World Health Organization $(4,5)$.

The development of quick, easy, cheap and reliable methods has become essential in diagnosis. There has been considerable research into new parameters that will contribute to the screening of diabetes. This current research includes studies on the utility of ketonic bodies, glycosylated $\mathrm{Hb}$, fructosamine, microalbumin and advanced glycation products to this end. Protein glycation and advanced glycation products play an important role in the development of diabetic complications, which include retinopathy, nephropathy, neuropathy, rheumatoid arthritis, cardiomyopathy, and osteoporosis. The accumulation of glycation end products on proteins and free amino acids has been associated with diabetic vascular, renal, retinal, and neural complications (6). At first, this non-enzymatic process is reversible, but later it becomes irreversible. The increase in circulating glycation end products may lead to renal insufficiency, and excretion of the metabolites in the urine. If the glycation end products accumulate in tissues, renal and microvascular complications can occur due to crosslinking with collagen. There is a need for more evidence before clinicians can routinely use these new diagnostic parameters as an alternative to OGTT. To this end, we investigated whether or not advanced glycation products have a role in IGT or GDM.

\section{Material and Methods}

Pregnant women, between 24-28 weeks of gestation who were being followed in the department of obstetrics and gynecology of a tertiary hospital, were taken to the clinical biochemistry laboratory for GDM screening, as recommended in the 2003 ADA guidelines (7). Fifty grams of glucose was given orally, at any time of day without consideration of fasting. One hour after glucose was administered, plasma glucose was measured by the glucose oxidase method. In this study, $140 \mathrm{mg} / \mathrm{dL}$ (7.8 $\mathrm{mmol} / \mathrm{L}$ ) was used as a threshold value for blood sugar in the plasma, as suggested by ADA and ACOG $(5,7)$. Following the administration of $50 \mathrm{~g}$ of oral glucose, if blood glucose level at the first hour was above this threshold, an OGTT using $100 \mathrm{~g}$ glucose was requested for definitive diagnosis.
Pregnant women who had type 1 and type 2 diabetes, multiple pregnancies, diagnosed endocrinopathies, kidney and liver disease, were under 18 years old, and pregnant women and who used drugs that could affect insulin secretion or susceptibility were excluded from the study group.

After $100 \mathrm{~g}$ OGTT, $95 \mathrm{mg} / \mathrm{dL}$ (5.3 mmol/L) of fasting glucose, 180 $\mathrm{mg} / \mathrm{dL}(10 \mathrm{mmol} / \mathrm{L})$ at one hour, $155 \mathrm{mg} / \mathrm{dL}(8.6 \mathrm{mmol} / \mathrm{L})$ at the second hour and $140 \mathrm{mg} / \mathrm{dL}(7.8 \mathrm{mmol} / \mathrm{L})$ at the third hour were used as the diagnostic criteria, as described by Carpenter and Couston (8) and Coustan (9), and GDM was diagnosed if any two values exceeding the threshold value. If any single value exceeded one of these threshold values, IGT was diagnosed.

The pregnant women who accepted to participate in the study were divided into three groups based on the diagnosis following the GDM screening tests. These groups were the GDM group, IGT group and a control group in whom the glucose concentration had remained below cut-offs at all time points. Then, fasting serum human advanced glycation end-products (AGEs), carboxymethyl lysine (CML) and advanced glycation product receptor (RAGE/AGER) levels were determined by ELISA methods, based on the antibody sandwich model.

All women gave informed consent to take part in the study. The study protocol was in compliance with the Declaration of Helsinki and approved by the local ethic committee. This study was supported by the Scientific Research Projects' Unit with the number of $2015 \mathrm{TF} / \mathrm{T}-211$.

\section{Statistical analysis}

SPSS, version 15.0 (IBM Inc., Armonk, NY, USA) program was used for statistical analysis. The distribution of data was evaluated by Kolmogorov-Smirnov method. ANOVA was used for comparison of normally distributed parameters and Kruskal-Wallis test was used for the comparison of nonnormally distributed parameters. Data are presented as mean \pm standard deviation. Chi-square test was used for comparison of qualitative data. The results were evaluated as $95 \%$ confidence interval and significance was assumed when $\mathrm{p}<0.05$.

\section{Results}

In total 180 pregnant women were included in the study. These were divided into three groups consisting of: 59 (32.8\%) GDM; 50 (27.8\%) IGT; and 71 (39.4\%) with no blood glucose metabolism impairments who constituted the control group. The groups did not differ statistically in terms of age, gestational week, gravida, parity, and living and abortus number. There was no statistically significant difference in diastolic blood pressure $(p=0.178)$ but systolic blood pressure was statistically significant between the groups $(\mathrm{p}=0.002)$ (Table 1$)$.

Fasting blood glucose (FBG) concentration, BMI values, occurrence of GDM in previous pregnancy and family history 
of DM were statistically significantly higher in the GDM group $(p=0.001)$. RAGE/AGER concentration differed significantly between the groups $(p<0.001)$. Pairwise group comparisons of the RAGE/AGER concentrations showed significant differences. CML and AGE levels between the control group, IGT and GDM groups were significantly different $(p<0.001)$ (Table 2$)$.

\section{Discussion}

In this study, the $50 \mathrm{~g}$ OGTT and $100 \mathrm{~g}$ OGTT tests performed between January 2015 and January 2016 in our hospital were compared and examined the levels of glucose degradation products and receptors in pregnant women diagnosed with GDM and IGT in IGT by comparison to a control group with no evidence of impaired glucose homeostasis in pregnancy. Our aim was to investigate whether glucose degradation products, including AGE, RAGE and CML, are useful for the early diagnosis of IGT or GDM. There was a significant difference in the levels of the markers between the three groups. In the literature, there are no other studies investigating the relationship between glucose degradation products and IGT and GDM.

The risk of diabetes in women at age 30 is $4.4 \%$ whereas at age 35 it is $6.5 \%$. In our study, the mean age of diabetic group was $32.34 \pm 5.43$ years, which was insignificantly older than the control group (30.93 $\pm 3.43 ; \mathrm{p}>0.05)$. In Dornhorst and Rossi's (10) study, age was accepted as one of the unchangeable risk factors. In our study, when we compared age groups, we found that patients with negative screening test were statistically younger than those with GDM and IGT group $(\mathrm{p}<0.0001)$. There was no statistical difference between the other groups. This finding confirms that older age is a risk factor for GDM (11).

As the number of pregnancies increased, there was no significant difference in diagnosis of GDM by $100 \mathrm{~g}$ OGTT. It has been shown that the number of pregnancies is not among the risk factors for GDM (International Diabetes Study group) (12). Of those questioned about diabetes in family history, 51.1\% had a positive diabetes story. In the absence of DM family history, the risk of diabetes is $4.4 \%$, while in cases of positive DM family history the risk increases to $8.8 \%$ (13). There is a risk of recurrence of GDM in subsequent pregnancies. In a prospective study, GDM repeated in 47 of 90 (52\%) pregnancies with GDM $(14,15)$. In our study, $16.2 \%$ of the cases had GDM history in previous pregnancies.

The risk is $3.6 \%$ when BMI is 22 while it increases to $8.6 \%$ when BMI is 25 . The risk also increases in positive family history with

Table 1. Clinical and anthropometric characteristics of the study groups

\begin{tabular}{|l|l|l|l|l|}
\hline Parameters & Control $(\mathbf{n = 7 1 )}$ & IGT (n=50) & GDM (n=59) & p \\
\hline Age (years) & $30.93 \pm 3.43$ & $32.92 \pm 5.46$ & $32.34 \pm 5.43$ & 0.059 \\
\hline BMI $\left(\mathrm{kg} / \mathrm{m}^{2}\right)$ & $27.58 \pm 4.64$ & $30.98 \pm 4.63$ & $33.43 \pm 5.96$ & $<0.001$ \\
\hline Gravida & $2(1-6)$ & $3(1-7)$ & $2(1-5)$ & NS \\
\hline Family history of DM & $2.8 \%$ & $20.9 \%$ & $28.8 \%$ & $<0.001$ \\
\hline History of GDM (\%) & $2.8 \%$ & $20.9 \%$ & $27.8 \%$ & $<1.7$ \\
\hline Gestational age (week) & $26.5 \pm 1.3$ & $27.2 \pm 1.8$ & $121.36 \pm 15.02$ & 0.689 \\
\hline Systole (mmHg) & $112.01 \pm 13.71$ & $116.96 \pm 16.71$ & $74.58 \pm 9.88$ & 0.002 \\
\hline Diastole (mmHg) & $70.75 \pm 14.30$ & $73.40 \pm 10.61$ & 0.178 \\
\hline $\begin{array}{l}\text { Data presented as mean } \pm \text { standard deviation, median [IQR] or proportions. Differences evaluated by non-parametric chi-square test, respectively. } \\
\text { IGT: Impaired glucose tolerance, GDM: Gestational diabetes mellitus, BMI: Body mass index, DM: Diabetes mellitus, NS: Non-significant }\end{array}$
\end{tabular}

Table 2. Laboratory characteristics of the study groups

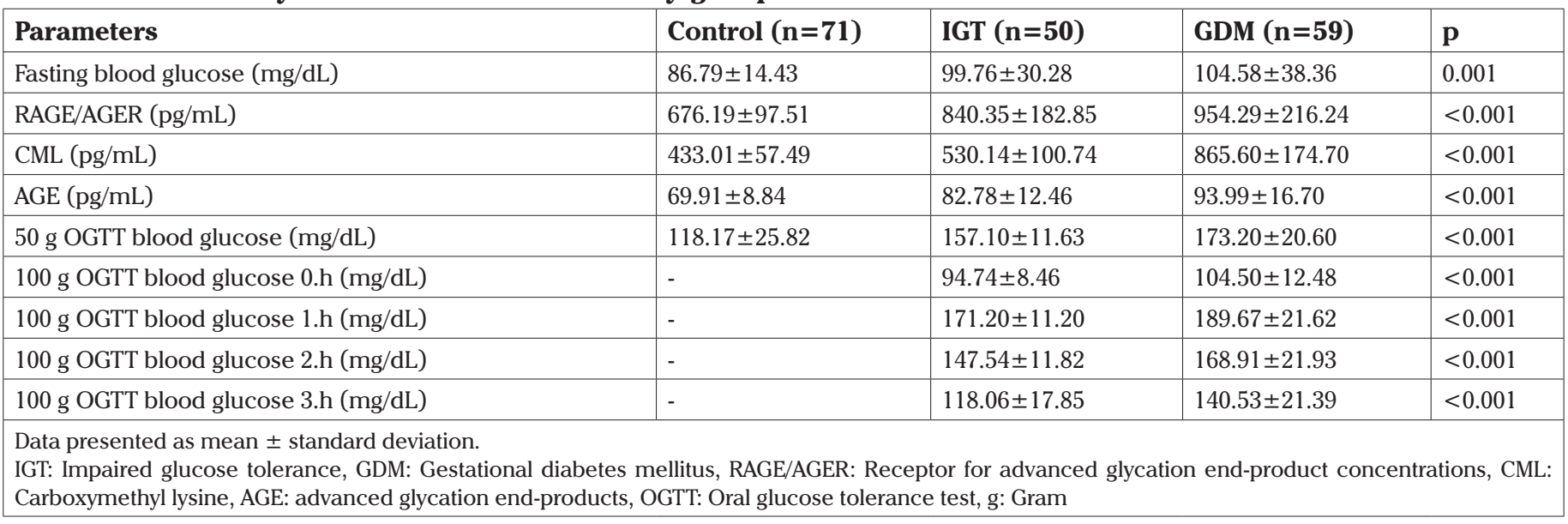


the weight gain of the person. In our study, $100 \mathrm{~g}$ OGTT results were worse in women with high BMI. Dudhbhai et al. (16) also found that elevated BMI was more common in pregnancies with poor $100 \mathrm{~g}$ OGTT results. In our study, we found that the fasting blood sugar of the first application was higher in 100 g OGTT defects and this value was statistically significant $(p<0.05)$. Perruchini et al. (17) also reported that the initial FBG was high in bad OGTT retrospectively.

The chronic hyperglycemia of diabetes leads to the formation of heterogeneous compounds known as AGEs. AGEs are formed as a result of non-enzymatic glycation of macromolecules, such as amino acids, proteins, peptides, phospholipids and nucleic acids. Diabetes-associated AGEs accumulate in tissues and lead to micro- and macro-complications of diabetes. Currently the structure of many AGE species has been clarified and it has become possible to identify them by using various properties (1823). Hemoglobin Alc (HbAlc) is one of the endogenously formed glycation products, resulting from the glycation of the $\mathrm{Hb}$ molecule. HbAlc concentration is not only used to diagnose diabetes but it is also used for follow-up in diabetic individuals and indirectly informs about blood glucose levels over the preceding 8-10 weeks. Without doubt AGEs are more suitable for the evaluation of total glycation products as the test cannot distinguish between exogenously and endogenously glycated products of all proteins and nucleic acids. The AGE test also reveals glycation products formed by fructose and galactose $(24,25)$.

The three groups were compared in terms of RAGE/AGER, CML and AGE values. The mean concentration of RAGE/AGER in the GDM group was significantly higher than that of the IGT group. Similarly, when CML levels were compared between the three groups this was found to be significantly higher in the GDM group compared with controls. A similar significant difference was found between the three groups for mean concentration of AGE with both the GDM and IGT groups having higher mean concentrations than the controls. The high CML and AGE levels in the GDM-diagnosed pregnancies supports similar results in previous studies (26-29).

AGE formation and its effects play an important role in the development of chronic complications of DM. A clear understanding of the structure of these heterogeneous compounds, standardization of measurement methods, and a clear understanding of the pathophysiology of long-term complications play a significant step in determining treatment options. Measurement of this emerging class of biomarkers may become a new tool in the monitoring the development of late complications from glycation in diabetic patients.

\section{Conclusion}

Currently, gestational diabetes screening, diagnosis, and followup methods are controversial. The significant differences in the mean levels of RAGE/AGER, CML and AGE in this study may indicate a use for them in future assessment of GDM. This will require further standardization of measurement protocols which may emerge following larger, prospective studies of utility in diabetes in general and in women being screened for GDM. Our results suggest that AGE, RAGE and CML values may contribute to early GDM diagnosis, but there is a need for extensive studies to determine sensitivity, specificity and suitability based on cost analysis in order to use these parameters in screening and diagnosis.

Ethics Committee Approval: The study protocol was in compliance with the Declaration of Helsinki and approved by the local ethic committee.

Informed Consent: All women gave informed consent to take part in the study.

Peer-review: Externally peer-reviewed.

Author Contributions: Surgical and Medical Practices: Ö.S.T., M.K.; Concept: Y.E.Ü., M.K.; Design: Y.E.Ü., A.Y.G.; Data Collection or Processing: Ö.S.T.; Analysis or Interpretation: M.K., A.Y.G.; Literature Search: Ö.Ş.T., A.Y.G.; Writing: Ö.Ş.T., M.K., A.Y.G., E.S.Y.

Conflict of Interest: No conflict of interest is declared by the authors.

Financial Disclosure: This study was supported by the Scientific Research Projects' Unit with the number of 2015TF/T-211.

\section{References}

1. Yalçin HR, Zorlu CG. Threshold value of glucose screening tests in pregnancy: could it be standardized for every population? Am J Perinatol 1996; 13: 317-20.

2. Gregory KD, Kjos SL, Peters RK. Cost of non-insulin-dependent diabetes in women with a history of gestational diabetes: implications for prevention. Obstet Gynecol 1993; 81: 782-6.

3. Khandelwal M, Homko C, Reece EA. Gestational diabetes mellitus: controversies and current opinions. Curr Opin Obstet Gynecol 1999; 11: 157-65.

4. Deerachanawong C, Putiyanun C, Wongswyat M, Serirat S, Jinayon P. Comparison of National Diabetes Data Group and World Health Organization criteria for detecting gestational diabetes mellitus. Diabetologia 1996; 39: 1070-3.

5. American College of Obstetricians and Gynecologists: Diabetes and pregnancy. ACOG Technical Bulletin. Washington, DC 1994.

6. Singh VP, Bali A, Singh N, Singh Jaggi A. Advanced glycation end products and diabetic complications. Korean J Physiol Pharmacol 2014; 18: 1-14.

7. American Diabetes Association. Gestational Diabetes Mellitus. Diabetes Care 2003; 26: 103-5.

8. Carpenter MW, Couston DR. Criteria for screening tests for gestational diabetes. Am J Obstet Gynecol 1982; 144: 768-73. 
9. Coustan DR. Diagnosis of gestational diabetes: What are our objectives? Diabetes 1991;40(Suppl 2): 14-7.

10. Dornhorst A, Rossi M. Risk and prevention of type 2 diabetes in women with gestational diabetes. Diabetes Care 1998; 21(Suppl 2): B43-9.

11. From the American Diabetes Association, Alexandria, Virginia. Originally approved 1997. Modified in 1999 based on the Proceedings of the Fourth International Workshop-Conference on Gestational Diabetes Mellitus. Diabetes Care 1998 ;21: 1-167.

12. Metzger BE, Couston DR. Proceedings of the Fourth İnternational Workshop- Conference on Gestational Diabetes Mellitus. Diabetes Care 1998; 21: 167.

13. Solomon CG, Willett WC, Carey VJ, Rich-Edwards J, Hunter DJ, Colditz GA, et al. A prospective study of pregravid determinants of gestational diabetes mellitus. JAMA 1997; 278: 1078-83.

14. Pallardo LF, Herranz L, Martin-Vaquero P, Garcia-Ingelmo T, Grande C, Jañez M. mpaired fasting glucose and impaired glucose tolerance in women with prior gestational diabetes are associated with a different cardiovascular profile. Diabetes Care 2003; 26: 2318-22.

15. Gaudier FL, Hauth JC, Poist M, Corbett D, Cliver SP. Recurrence of gestational diabetes mellitus. Obstet Gynecol 1992; 80: 755-8.

16. Dudhbhai M, Lim L, Bombard A, Juliard K, Meenakshi B, Trachelenberg Y, et al. Characteristics of patients with abnormal glucose challenge test and normal oral glucose tolerance test results: comparison with normal and gestational diabetic patients. Am J Obstet Gynecol 2006; 194: e42-5.

17. Perruchini D, Fischer U, Spinas GA, Huch R, Huch A, Lehmann R. Using fasting plasma glucose concentrafions to screen for gestational diabetes mellitus. BMJ 1999; 319: 812-5.

18. Thomally PJ. Cell activation by glycated proteins. AGE receptors, receptor recognition factors and functional classification of AGEs. Cell Mol Biol 1998; 44: 1013-23.

19. Thomalley PJ, Battah S, Ahmed N, Karachalias N, Agalou S, BabaeiJadidi R, et al. Quantitative screening of advanced glycation endproducts in cellular and extrasellular proteins by tandem mass spectrometry. Biochem J 2003; 375: 581-92.
20. Vlasaara $\mathrm{H}$. The AGE receptor in the pathogenesis of diabetic complications. Diabetes Meteb Res Rev 2001; 17: 436-43.

21. Wells-Knecht KJ, Brinkmann E, Wells-Knecht MC, Litchfield JE, Ahmed MU, Reddy S, et al. New biomarkers of Maillard reaction damage to proteins. Nephrol Dial Transplant 1996; 11(Suppl 5): 417.

22. Njoroge FG, Monier WM. The chemistry of the Maillard reaction under physiological conditions: a review. Prog Clin Biol Res 1989; 304: 85-107.

23. Zhang Q, Ames JM, Smith RD, Baynes JW, Metz TO. A perspective on the Maillard reaction and the analysis of protein glycation by mass spectrometry: probing the pathogenesis of chronic disease. $\mathrm{J}$ Proteome Res 2009; 8: 754-69.

24. Schiekofer S, Andrassy M, Chen J, Rudofsky G, Schneider J, Wendt $\mathrm{T}$, et al. Acute hyperglycemia causes intracellular formation of CML and activation of ras, p42/44 MAPK, and nuclear factor kappaB in PBMCs. Diabetes 2003; 52: 621-33.

25. Sakai M, Oimomi M, Kasuga M. Experimental studies on the role of fructose in the development of diabetic complications. Kobe J Med Sci 2002; 48: 125-36.

26. Li S, Yang $\mathrm{H}$. Relationship between advanced glycation end products and gestational diabetes mellitus. J Matern Fetal Neonatal Med 2019; 32: 2783-9.

27. Bartakova V, Kollarova R, Kuricova K, Sebekova K, Belobradkova J, Kankova K. Serum carboxymethyl-lysine, a dominant advanced glycation end product, is increased in women with gestational diabetes mellitus. Biomed Pap Med Fac Univ Palacky Olomouc Czech Repub 2016; 160: 70-5.

28. Lobo JP Júnior, Brescansin CP, Santos-Weiss ICR, Welter M, Souza EM, Rego FGM, et al. Serum Fluorescent Advanced Glycation End (F-AGE) products in gestational diabetes patients. Arch Endocrinol Metab 2017; 61: 233-7.

29. Cosson E, Gary F, Nguyen MT, Bianchi L, Sandre-Banon D, Biri L, et al. Gradual increase in advanced glycation end-products from no diabetes to early and regular gestational diabetes: A case-control study. Diabetes Metab 2019; 45: 586-9. 